\title{
The Effect of E-WOM Receivers' Envy on Their Behavior Through Social Networking Site: An Abstract
}

\author{
Akinori Ono and Ryosuke Shimizu
}

\begin{abstract}
Previous research has shown that if WOM (word-of-mouth) receivers are exposed to a video message in which a person says that he/she made great efforts to earn money and purchase an attractive product, they feel benignly envious and have higher WTP (willingness to pay) for the product. In contrast, if receivers are exposed to another message in which a person says that he/she made no effort to earn money and purchase the product, they feel maliciously envious and have a higher WTP for other products.

These findings suggest that positive WOM messages may have negative impacts on WOM receivers' WTP due to envy. However, previous experiments have mainly used video messages sent by unknown persons, which are different from e-WOM messages sent through SNS (social networking sites). (1) While video messages in previous research came from unknown persons, e-WOM messages sometimes come from "friends." (2) While video messages are always made by product buyers, e-WOM messages sometimes come from manufacturers who have permission to send messages on behalf of the buyers. (3) While video message receivers in previous research could only choose not to buy the envy-eliciting product, e-WOM receivers can choose other malicious behaviors such as posting a negative comment or not pressing the "like" button instead.

The results of three laboratory experiments showed that in the context of e-WOM, unlike the situation in face-to-face WOM, (1) receivers were less likely to feel maliciously envious toward friends and have WTP for the product; (2) receivers were less likely to feel maliciously envious if they were exposed to the message as a tool for marketing; and (3) receivers were less likely to avoid the envy-eliciting product if they have any other measures of retaliation. This research contributes to progress in the research field of e-WOM through SNS.
\end{abstract}

\footnotetext{
A. Ono $(\bowtie) \cdot$ R. Shimizu

Keio University, Tokyo, Japan

e-mail: akinori@keio.jp; s.r1557.com@gmail.com
} 